\section{A BESPOKE CONTROL SYSTEM}

Bien-Air's 'click and work' philosophy is a new approach to your endodontic needs. The Optima MX INT is an interface that enables you to start treatment in a single click and enables you to change the treatment settings in just a few clicks. You can perform root treatments safely with a significantly reduced risk of instrument breakage due to the auto reverse function.

With an easy to use, intuitive display the Optima MX INT converts your air-driven system to an upgraded electric operation, allowing, for example, NiTi endodontics to be covered with a standard 1:1 contra-angled handpiece. Thanks to the unique performance of the motor and control systems most other procedures are covered with just two contra-angles (1:1 and 1:5), reducing the number of conventional instruments used in the surgery saving time, bother and expense. The system can be quickly and easily tailored to your individual requirements. Reader response number 58

\section{NEW SPORTS MOUTHWEAR RANGE LAUNCHING}

Nuview is launching an exciting new sports mouthwear range at this year's British Dental Conference and Exhibition on 19-21 May in Manchester:

1. Under Armour Performance

Mouthwear - a new concept in improving performance in sport and other environments. Under Armour mouthguards, for contact sports, and mouthpieces, for non-contact sports, incorporate a patented ArmourBite Power Wedge engineered to unlock the full athletic potential of your active patients

2. Carl Zeiss Magnification Equipment - this impressive range will be presented by Nuview's dedicated team of experts. See first hand how

\section{RESPECTING THE CANAL'S MORPHOLOGY}

Dentsply's new system of rotary endodontic files, WaveOne, uses the strength of M-Wire NiTi, created using an innovative thermal treatment process.

M-Wire NiTi files offer greater flexibility and respect the canal's true morphology whilst reducing the chance of cyclic fatigue and file separation. Practitioners will require one rotary single-use NiTi file to complete an entire procedure in the majority of cases.

The WaveOne system also: allows the clinician greater control while preparing the canal; is simple and easy the award winning OPMI Pico dental microscope has earned its outstanding reputation amongst professionals for improved posture and enhanced treatment and diagnoses, and how cutting edge surgical loupes such as the EyeMag Pro can raise the bar in your everyday clinical practice

3. Continu Water-Based Disinfectants - also on display will be Nuview's alcohol-free disinfection range which achieves a 99.998\% kill rate within 30 seconds yet has the same hazard rating as water. Whatever your disinfection needs, Continu delivers a range of innovative HTM 01-05 compliant solutions.

Nuview will be on stand C35. Reader response number 59

to use; is able to prepare teeth quickly and reliably; is a highly cost effective system; and is created by endodontic experts with years of experience. Reader response number 60

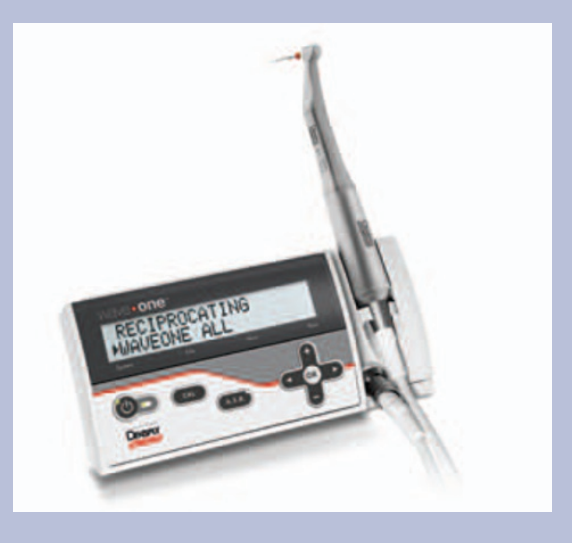

